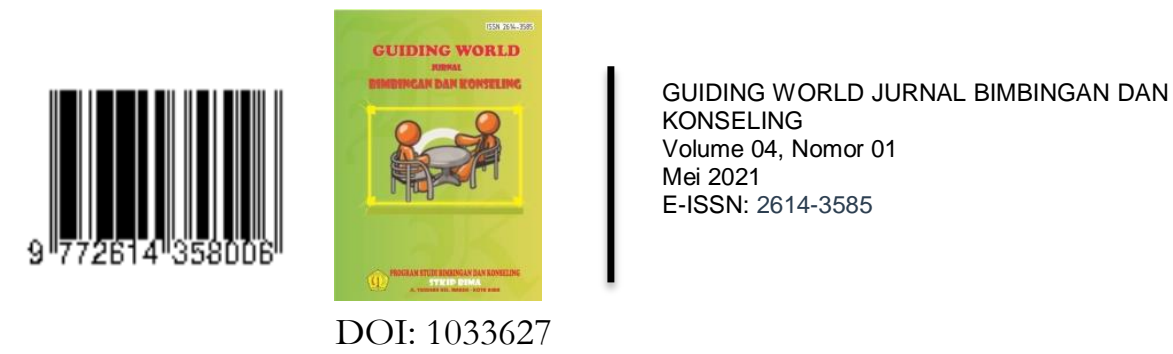

\title{
Efektivitas Penerapan Ice Breaking Untuk Mengatasi Kejenuhan Mahasiswa Dalam Pembelajaran BK Kelompok
}

\section{Effectiveness of Ice Breaking Application to Overcome Student Boredom in Group BK Learning}

\author{
Faijin $^{1}$, Alya Nurmaya ${ }^{2}$, Muhamadiah ${ }^{3}$ \\ Prodi Bimbingan dan Konseling, STKIP Bima \\ Email: wongfaiijin@gmail.com
}

\begin{abstract}
Abstrak: Penelitian ini dilatarbelakangi munculnya berbagai perilaku mahasiswa pada saat kegiatan pembelajaran berlangsung. Perilaku tersebut berupa adanya perasaan acuh tak acuh dalam mengamati pelajaran yang diberikan, kurang semangat, selalu gelisah, rasa enggan, malas, lesu dan merasa tidak bergairah dalam belajar. Tujuan penelitian adalah untuk mengetahui efektivitas ice breaking dalam mengatasi kejenuhan mahasiswa dalam pembelajaran BK kelompok. Tehnik pengumpulan data menggunakan angket dan observasi. Sampel penelitian adalah 20 orang mahasiswa yang dibagi menjadi 2 kelompok yaitu kelompok eksperimen 10 orang dan kelompok control 10 orang. Penelitian ini menggunakan pendekatan eksperimen (true eksperimen desain) dalam bentuk pretes-postes kontrol grup desain. Analisis data yang di gunakan adalah uji wilccoxon dengan analisis statistic deskriptif nonparametrik. Hasil perhitungan statistik uji Wilcoxon Signed Rank Test (WSRT) diperoleh nilai Asymp. Sig. (2-tailed) sebesar 0.005 lebih kecil dari taraf signifikansi $0.05 \quad(0.005<0.05)$ maka hipotesis yang diajukan yang berbunyi ice breaking efektiv dalam mengatasi kejenuhan mahasiswa dalam pembelajaran $B K$ kelompok dapat diterima.
\end{abstract}

Kata Kunci: Ice Breaking; Kejenuhan belajar

Abstract: This research is motivated by the emergence of various student behaviors during learning activities. This behavior is in the form of a feeling of indifference in observing the lessons given, lack of enthusiasm, always being anxious, reluctant, lazy, lethargic and not feeling passionate about learning. The research objective was to determine the effectiveness of ice breaking in overcoming student boredom in group counseling learning. Data collection techniques used questionnaires and observations. The research sample was 20 students who were divided into 2 groups, namely the experimental group 10 
people and the control group 10 people. This study used an experimental approach (true experimental design) in the form of a pretest-posttest control group design. The data analysis used was the Wilccoxon test with nonparametric descriptive statistical analysis. The results of the statistical calculation of the Wilcoxon Signed Rank Test (WSRT) obtained the Asymp value. Sig. (2-tailed) of 0.005 which is smaller than the significance level of $0.05(0.005<0.05)$, then the hypothesis that says ice breaking is effective in overcoming student boredom in group BK learning can be accepted.

Keywords: Ice Breaking, Saturation Of Learning

\section{PENDAHULUAN}

Pendidikan dan mahasiswa merupakan satu kesatuan yang selalu terkait. Sebagai kaum intelektual, kualitas diri dalam hal pendidikan harus terus ditingkatkan supaya mutu bangsa Indonesia juga bertambah berdasarkan ilmu yang dipelajari selama jenjang pendidikan didunia kampus. Dengan pendidikan, mahasiswa punya dasar berpikir yang benar dalam memutuskan berbagai hal didunia kampus maupun pasca kampus. Pola berpikir yang benar umumnya diperoleh selama menempuh masa pendidikan melalui berbagai proses belajar mengajar dan pengalaman peribadi. Pendidikan yang ditempuh sesuai dengan pilihan program studi yang disediakan oleh setiap universitas/perguruan tinggi dimana nantinya akan menjadi fokus mahasiswa dalam mengembangkan dan menerapkan ilmu pengetahuannya.

Tujuan penelitian adalah untuk mengetahui efektivitas ice breaking dalam mengatasi kejenuhan mahasiswa dalam pembelajaran BK kelompok. Penelitian ini diperkuat dengan hasil penelitian yang dilakukan oleh Elfa Rosyida Mahfud yang berjudul Strategi guru dalam mengatasi rasa jenuh siswa kelas 2A full day school sekolah dasar islam Tompokersan Lumajang, hasil penelitian yang dilakukan oleh Miftahur Reza Irachmat dengan judul Peningkatan perhatian siswa pada proses pembelajaran kelas III melalui permainan Ice Breaking di SDN Gembongan kec. Sentolo Kab. Kulon Progo, serta hasil penelitian oleh Suryanti yang berjudul Pengaruh Ice Breaking terhadap motivasi belajar kimia siswa kelas $X$ semester 2 di SMAN 10 Yogyakarta.

Persoalan kejenuhan belajar menjadi problem yang bisa dialami oleh setiap individu dan perlu mendapat perhatian khusus dari semua pihak untuk mendukung ketercapaian hasil belajar mahasiswa. Maka dari itu seorang dosen hendaknya mengetahui kondisi mahasiswa yang diajarnya ketika mengalami rasa bosan dan mencari solusi agar saat proses belajar rasa bosan tersebut dapat diatasi. Hipotesis dalam penelitian ini adalah ice breaking sangat efektiv dalam mengatasi kejenuhan mahasiswa dalam belajar.

Proses pendidikan yang dilakukan pada lingkungan formal maupun nonformal tidak dapat dipisahkan dari proses pembangunan itu sendiri. Pembangunan diarahkan dan bertujuan untuk mengembangkan sumber daya manusia yang berkualitas dan pembangunan sektor ekonomi, yang satu dengan yang lainya saling berkaitan dan berlangsung secara berbarengan. Berbicara tentang proses pendidikan sudah tentu tak dapat dipisahkan dengan semua upaya yang harus dilakukan untuk mengembangkan sumber daya manusia yang berkualitas, sedangkan manusia yang berkualitas itu dapat dilihat dari segi pendidikan seperti yang telah terkandung dalam fungsi dan tujuan pendidikan nasional. Perguruan 
tinggi adalah sebuah institusi yang tidak sekedar untuk kuliah, mencatat pelajaran, pulang dan tidur. Tapi harus dipahami bahwa perguruan tinggi adalah tempat untuk penggemblengan mahasiswa dalam melakukan kontempelasi dan penggambaran intelektual agar mempunyai idealisme dan komitmen perjuangan sekaligus tuntutan perubahan. Untuk itu mahasiswa dituntut untuk memiliki kemampuan personal maupun sosial dalam menjalankan tri darma perguruan tinggi yaitu pendidikan, penelitian dan pengabdian masyarakat. Akan tetapi dalam proses pembelajaranya mahasiswa sering kali muncul rasa bosan. Kebosanan yang dialami mahasiswa jika tidak bisa diatasi tentu akan membawa dampak negatif dalam proses belajarnya. Kejenuhan dalam belajar ialah rentang waktu tertentu yang digunakan untuk belajar tetapi tidak mendatangkan hasil (Reber, 1988). Belajar adalah kata yang tidak asing lagi, terutama di kalangan pelajar dan mahasiswa. Masing-masing mempunyai cara belajar yang berbeda-beda. Ada yang betah belajar berlama-lama, ada yang hanya sebentar, bahkan ada pula yang melihat buku saja seperti alergi sehingga tidak mau belajar. Rasa jenuh saat belajar juga sering kali terfikirkan dan membuat kita jadi malas belajar. Kejenuhan belajar dapat melanda seseorang apabila ia telah kehilangan motivasi dan kehilangan konsolidasi (Chaplin, 1972). Selain itu, kejenuhan juga dapat terjadi karena proses belajar siswa telah sampai pada batas kemampuan jasmaniahnya karena bosan (boring) dan keletihan (fatigue). Namun, penyebab kejenuhan yang paling umum adalah keletihan yang melanda siswa, karena keletihan dapat menjadi penyebab munculnya perasaan bosan pada individu yang bersangkutan. Menurut Cross (1974) dalam bukunya The Psychology of Learning, keletihan siswa dapat dikategorikan menjadi tiga macam yakni: 1. Keletihan indera 2. Keletihan fisik 3. Keletihan mental. Kejenuhan merupakan masalah semua orang. Untuk itu kita dituntut memiliki pengetahuan dan keterampilan yang memadai untuk mengatasi masalah kejenuhan. Paling tidak dengan bekal pengetahuan yang dimiliki, seseorang bisa terhindar risiko-risiko buruk dibalik kejenuhan.

Ada beberapa prinsip penting yang perlu dipahami sebelum kita melangkah mencari solusi-solusi konkret atas problema kejenuhan. Prinsip-prinsip itu merupakan arahan untuk menyikapi kejenuhan secara bijaksana. Secara berurutan prinsip-prinsip tersebut adalah sebagaiberikut:

1. Perubahan suasana. Kejenuhan terjadi karena suasana yang berulang-ulang (monoton) maka inti solusi dari problema kejenuhan adalah perubahan suasana. Kita harus mau keluar dari suasana lama yang mengelilingi, lalu masuk ke suasana yang baru yang lebih segar dan dinamis.

2. Kesegaran. Dengan adanya kesegaran itu, kita merasakan semangat (spirit) yang tinggi. Segala sesuatu yang kaku, monoton dan sejenisnya cenderung tidak disukai, sebab semua itu berpengaruh menurunkan semangat.

Seorang yang mengalami kejenuhan belajar merasa seakan-akan pengetahuan dan kecakapan yang diperoleh dari belajar tidak ada kemajuan. Keadaan kejenuhan dalam belajar dapat dilihat dari perilaku mahasiswa yang ditandai dengan perasaan acuh tak acuh dalam mengamati pelajaran yang diberikan, kurang semangat, selalu gelisah,rasa enggan, malas, lesu dan tidak bergairah dalam belajar. Kejenuhan adalah keadaan dimana pikiran menginginkan perubahan, mendambakan sesuatu yang baru dan menginginkan berhentinya rutinitas hidup dan keadaan yang monoton dari waktu ke waktu. Dan pasti setiap manusia pernah mengalaminya. Kejenuhan sangat berpengaruh seperti penyakit, melemahkan semangat, meluruhkan kekuatan (tekad). Kejenuhan banyak menimbulkan dampak negatif yang selama ini bayak dirasakan, diantaranya: 1. Sebagai penyakit. Kejenuhan dapat menghalang orang untuk melanjutkan pekerjaan, ia tidak memiliki cukup tekad untuk menuntaskan pekerjaan, kita harus menyikapnya secara bijaksana agar penyakit ini tidak berlanjut. 2.Produktifitas menurun. 
Ketika orang merasa jenuh, saat itu produktifitas kerjanya menurun. Seseorang yang merasa jenuh dalam belajar, semangatnya luntur, dan ingin melakukan hal-hal lain untuk mengusir kejenuhan. 3. Rencana gagal. Kejenuhan bisa mengacaukan rencana yang sudah disusun. Sebuah rencana mungkin sudah dipersiapkan dengan sangat baik, namun kejenuhan yang tiba-tiba muncul ditengah jalan, bisa menjadi musibah yang sangat menyakitkan. 4. Hasil tidak matang. Kerja maksimal akan diperoleh ketika seseorang mampu mempertahankan irama kerja, dan menjauhkan dari kejenuhan. 5. Muncul sikap usil. Seseorang merasa jenuh dengan keadaan yang ada, kemudian dia mencari hiburanhiburan segar dengan cara berbuat usil kepada orang-orang yang ada disekitarnya. 6. Sikap antipati. Kejenuhan juga bisa menimbulkan sikap antipati yaitu kebencian yang luar biasa terhadap seba-sebab yang menimbulkan kejenuhan. Tentu ini lebih serius daripada dampak yang lain. 7. Mencari pelarian. Berbeda dengan sikap antipati, orang yang jenuh namun tidak berdaya melawan kejenuhan itu, maka dalam kondisi seperti itu, apa yang sering orang lakukan adalah mencari pelarian. Mereka akan melakukan apa saja untuk menghibur diri. 8. Memicu kezhaliman. Kejenuhan luar biasa juga biasa memicu orang untuk berbuat kezhaliman terhadap orang lain. Kejenuhan adalah tekanan, maka setiap orang membenci tekanan itu. Banyak cara yang ditempuh untuk membebaskan diri dari tekanan, kalau perlu dengan cara mengorbankan orang lain. 9. Menimbulkan frustasi. Dampak paling serius dari kejenuhan adalah frustasi. Tekanan yang sangat berat tidak mampu diatasi dengan cara apapun. Dalam keadaan demikian orang kehilangan kepercayaan terhadap hidup yang dia jalani.

\section{METODE}

Metode penelitian ini merupakan penelitian kuantitatif dengan pendekatan eksperimen (True eksperimen design) model pretest-postest control group design.

\begin{tabular}{cccc}
\hline Kelompok & Pre-Test & Treatmen & Post-Test \\
\hline $\mathrm{R}$ & 01 & $\mathrm{X}$ & 02 \\
$\mathrm{R}$ & 03 & - & 04
\end{tabular}

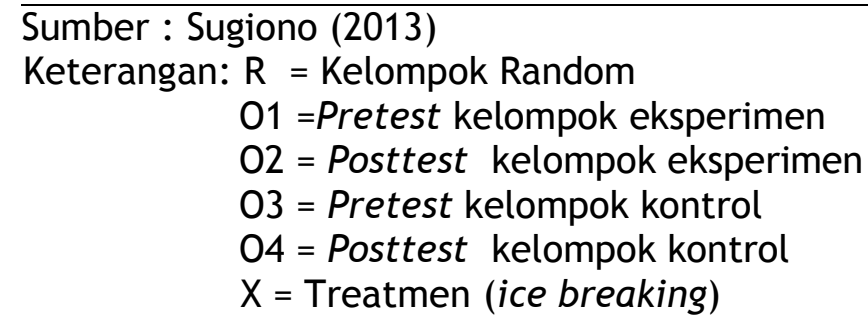

Penelitian ini mengkaji efektifitas ice breaking dalam mengatasi kejenuhan mahasiswa dalam belajar. Penelitian dilaksanakan pada mahasiswa STKIP Bima. Populasi dalam penelitian ini sebanyak 184 orang dengan sampel 20 orang. Tehnik sampling yang digunakan adalan stratified random sampling. bahan treatmen berupa ice breaking terdiri dari (1) siapa dia, (2) kisah angka-angka, (3) mencari jodoh, (4) bercermin, dan (5) menghitung mundur. Tehnik analisis data dalam penelitian ini menggunakan analisis observasi, analisis statistik deskriptif dan analisis statistik inferensial uji Wilcoxon dengan bantuan SPSS 20. 


\section{HASIL DAN PEMBAHASAN}

Kejenuhan belajar dapat melanda siapa saja, seorang yang mengalami hal ini merasa kehilangan motivasi dan konsolidasi diri sebagai salah satu tingkat keterampilan tertentu sebelum sampai pada tingkat keterampilan berikutnya. Seorang yang sedang dalam keadaan jenuh sistem akalnya tidak dapat bekerja sebagaimana yang diharapkan dalam memproses item-item informasi atau pengalaman baru, sehingga kemajuan belajarnya seakan-akan jalan di tempat. Hasil penelitian terhadap 10 orang mahasiswa kelompok eksperimen dan 10 orang mahasiswa kelompok kontrol pada saat pretest menunjukkan bahwa tingkat kejenuhan mahasiswa berada pada kategori tinggi. Tingginya rasa jenuh juga dapat dilihat dari perilaku mahasiswa seperti adanya perasaan acuh tak acuh dalam mengamati pelajaran yang diberikan, kurang semangat, selalu gelisah, rasa enggan, malas, lesu dan merasa tidak bergairah dalam belajar. Keadaan data hasil penelitian terhadap kelompok eksperimen dan kelompok kontrol adalah sebagai berikut:

Hasil Analisis Kelompok Eksperimen

Descriptive Statistics

\begin{tabular}{|l|r|r|r|r|r|}
\hline & $\mathrm{N}$ & Minimum & Maximum & Mean & $\begin{array}{c}\text { Std. } \\
\text { Deviation }\end{array}$ \\
\hline item1 & 10 & 1.00 & 2.00 & 1.5000 & .52705 \\
item2 & 10 & 1.00 & 3.00 & 1.9000 & .56765 \\
item3 & 10 & 2.00 & 4.00 & 2.4000 & .69921 \\
item4 & 10 & 1.00 & 3.00 & 1.9000 & .56765 \\
item5 & 10 & 1.00 & 4.00 & 2.2000 & .78881 \\
item6 & 10 & 2.00 & 4.00 & 2.9000 & .56765 \\
item7 & 10 & 2.00 & 3.00 & 2.1000 & .31623 \\
item8 & 10 & 1.00 & 3.00 & 1.6000 & .69921 \\
item9 & 10 & 1.00 & 4.00 & 2.0000 & .94281 \\
item10 & 10 & 1.00 & 3.00 & 2.3000 & .67495 \\
item11 & 10 & 2.00 & 4.00 & 2.8000 & .91894 \\
item12 & 10 & 1.00 & 3.00 & 2.6000 & .69921 \\
item13 & 10 & 1.00 & 3.00 & 2.1000 & .73786 \\
item14 & 10 & 1.00 & 3.00 & 1.9000 & .87560 \\
item15 & 10 & 1.00 & 4.00 & 2.6000 & 1.07497 \\
item16 & 10 & 1.00 & 3.00 & 2.3000 & .82327 \\
item17 & 10 & 1.00 & 4.00 & 2.8000 & 1.13529 \\
item18 & 10 & 1.00 & 4.00 & 2.6000 & .84327 \\
item19 & 10 & 2.00 & 4.00 & 2.6000 & .69921 \\
item20 & 10 & 2.00 & 4.00 & 3.0000 & .66667 \\
item21 & 10 & 1.00 & 3.00 & 2.1000 & .56765 \\
item22 & 10 & 1.00 & 3.00 & 1.9000 & .87560 \\
item23 & 10 & 1.00 & 3.00 & 2.2000 & .63246 \\
item24 & 10 & 1.00 & 3.00 & 2.3000 & .67495 \\
item25 & 10 & 1.00 & 3.00 & 2.2000 & .63246 \\
item26 & 10 & 1.00 & 3.00 & 2.1000 & .73786 \\
item27 & 10 & 1.00 & 3.00 & 2.1000 & .56765 \\
item28 & 10 & 2.00 & 3.00 & 2.3000 & .48305 \\
item29 & 10 & 1.00 & 3.00 & 2.4000 & .69921 \\
& & & & & \\
\hline
\end{tabular}




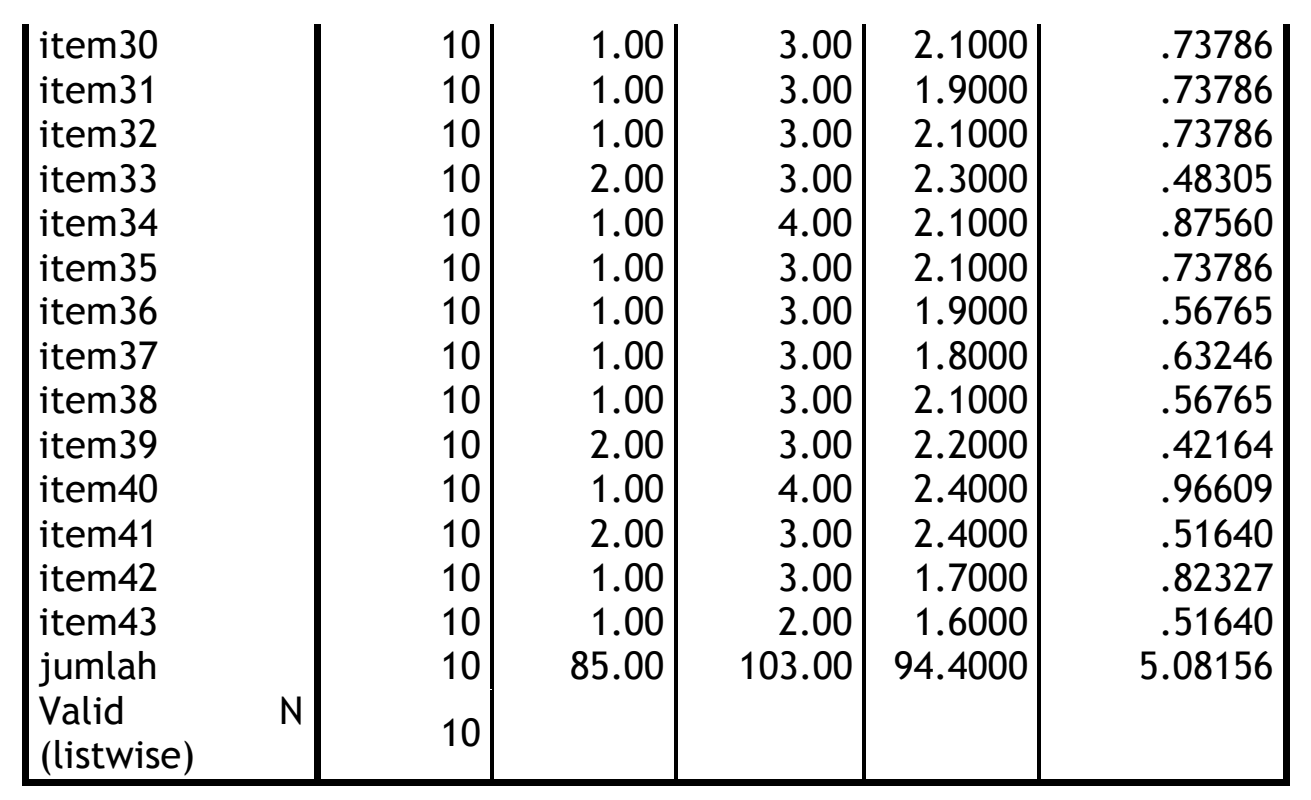

Hasil Analisis Kelompok Kontrol

\begin{tabular}{|l|r|r|r|r|r|}
\hline \multicolumn{7}{|c|}{ Descriptive Statistics } \\
\hline item1 & $\mathrm{N}$ & Minimum & Maximum & Mean & $\begin{array}{c}\text { Std. } \\
\text { Deviation }\end{array}$ \\
item2 & 10 & 1.00 & 2.00 & 1.2000 & .42164 \\
item3 & 10 & 1.00 & 3.00 & 1.8000 & .78881 \\
item4 & 10 & 1.00 & 4.00 & 2.5000 & 1.08012 \\
item5 & 10 & 1.00 & 3.00 & 2.2000 & .78881 \\
item6 & 10 & 2.00 & 3.00 & 2.4000 & .51640 \\
item7 & 10 & 2.00 & 3.00 & 2.5000 & .52705 \\
item8 & 10 & 1.00 & 4.00 & 2.5000 & .84984 \\
item9 & 10 & 1.00 & 3.00 & 2.2000 & .78881 \\
item10 & 10 & 1.00 & 3.00 & 1.9000 & .87560 \\
item11 & 10 & 1.00 & 3.00 & 1.9000 & .73786 \\
item12 & 10 & 2.00 & 4.00 & 2.4000 & .69921 \\
item13 & 10 & 1.00 & 3.00 & 2.4000 & .69921 \\
item14 & 10 & 1.00 & 3.00 & 2.2000 & .63246 \\
item15 & 10 & 1.00 & 3.00 & 2.2000 & .63246 \\
item16 & 10 & 1.00 & 3.00 & 2.4000 & .69921 \\
item17 & 10 & 1.00 & 3.00 & 2.5000 & .70711 \\
item18 & 10 & 1.00 & 3.00 & 2.3000 & .67495 \\
item19 & 10 & 2.00 & 4.00 & 2.3000 & .67495 \\
item20 & 10 & 1.00 & 3.00 & 2.2000 & .78881 \\
item21 & 10 & 2.00 & 4.00 & 3.0000 & .81650 \\
item22 & 10 & 1.00 & 3.00 & 1.8000 & .78881 \\
item23 & 10 & 1.00 & 3.00 & 1.9000 & .87560 \\
item24 & 10 & 2.00 & 3.00 & 2.2000 & .42164 \\
item25 & 10 & 1.00 & 3.00 & 2.4000 & .69921 \\
item26 & 10 & 1.00 & 3.00 & 2.0000 & .47140 \\
item27 & 10 & 1.00 & 3.00 & 2.1000 & .73786 \\
& 10 & 2.00 & 3.00 & 2.5000 & .52705
\end{tabular}

Faijin, Alya Nurmaya, Muhamadiah

Efektivitas Penerapan Ice Breaking Untuk Mengatasi

Kejenuhan Mahasiswa Dalam Pembelajaran BK

Jurnal Guiding World

Vol. 04 No. 01. Mei 2021: Hal 01-10 


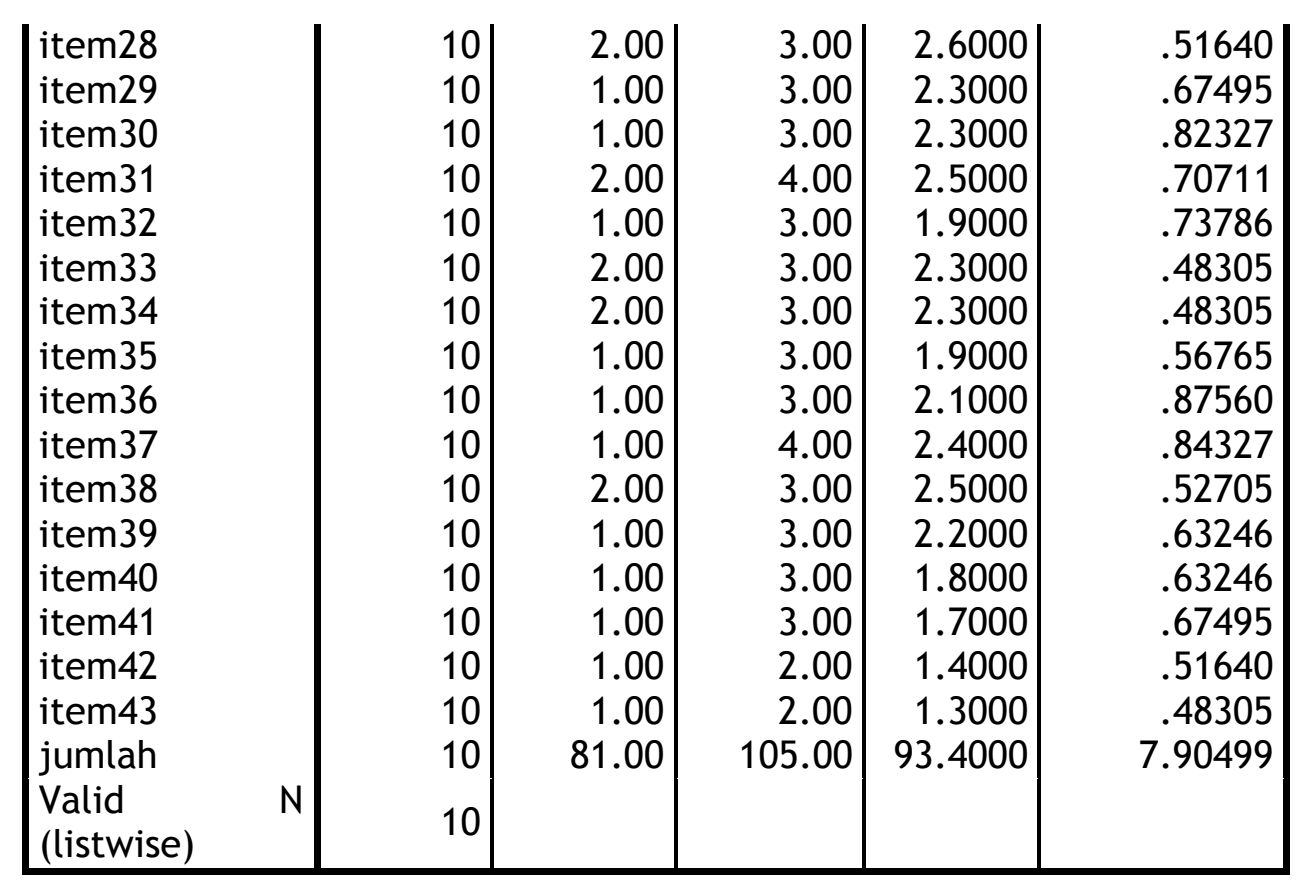

Hasil perhitungan statistik uji Wilcoxon Signed Rank Test (WSRT) diperoleh nilai Asymp. Sig. (2-tailed) sebesar 0.005 lebih kecil dari taraf signifikansi 0.05 $(0.005<0.05)$ maka hipotesis yang diajukan yang berbunyi ice breaking efektiv dalam mengatasi kejenuhan mahasiswa dalam pembelajaran BK kelompok dapat diterima. Penelitian ini menggunakan pendekatan eksperimen (true eksperimen desain) dalam bentuk pretes-postes kontrol grup desain. Analisis data yang di gunakan adalah uji wilccoxon dengan analisis statistic deskriptif nonparametrik.

Distribusi Tingkat Kejenuhan Mahasiswa Sebelum (Pretest) dan Setelah (Postest) pada kelompok Eksperimen

\begin{tabular}{cccccc}
\hline \multirow{2}{*}{ Interval } & Kategori & \multicolumn{2}{c}{ Pretest Eksperimen } & \multicolumn{2}{c}{ Postest Eksperimen } \\
\cline { 3 - 6 } & & Frekuensi & Persentase & Frekuensi & Persentase \\
\hline $\begin{array}{c}183- \\
217\end{array}$ & $\begin{array}{c}\text { Sangat } \\
\text { tinggi }\end{array}$ & 1 & $10 \%$ & 0 & $0 \%$ \\
$148-$ & Tinggi & 8 & $80 \%$ & 0 & $0 \%$ \\
182 & Sedang & 1 & $10 \%$ & 1 & $10 \%$ \\
$113-$ & 0 & $0 \%$ & 9 & $90 \%$ \\
$78-112$ & Rendah & 0 & $0 \%$ & 0 & $0 \%$ \\
$43-77$ & Sangat & 0 & $100 \%$ & 10 & $100 \%$ \\
\hline Jumlah & & 10 & & & \\
\hline
\end{tabular}


Sumber: Hasil skala kelompok eksperimen

Distribusi Tingkat Kejenuhan Mahasiswa hasil Pretest dan Postest pada Kelompok Kontrol.

\begin{tabular}{cccccc}
\hline \multirow{2}{*}{ Interval } & Kategorisasi & \multicolumn{2}{c}{ Pretest Kontrol } & \multicolumn{2}{c}{ Postest Kontrol } \\
\cline { 2 - 6 } & Frekuensi & Persentase & Frekuensi & Persentase \\
\hline $\begin{array}{c}183-217 \\
148-182\end{array}$ & $\begin{array}{c}\text { Sangat tinggi } \\
\text { Tinggi }\end{array}$ & 0 & $0 \%$ & 0 & $0 \%$ \\
$78-147$ & Sedang & 10 & $100 \%$ & 8 & $80 \%$ \\
$43-77$ & Rendah & 0 & $0 \%$ & 2 & $20 \%$ \\
& Sangat rendah & 0 & $0 \%$ & 0 & $0 \%$ \\
\hline Jumlah & & 0 & $0 \%$ & 0 & $0 \%$ \\
\hline
\end{tabular}

Sumber: Hasil skala kelompok kontrol

Suatu pekerjaan yang dilakukan dengan perasaan senang akan menimbulkan perasaan senang juga . Begitu juga dengan kegiatan belajar, apabila merasa senang, maka akan memiliki gairah dan semangat untuk belajar. Lama kelamaan perasaan jenuh akan terkikis dan hilang. Belajar juga menguras tenaga dan pikira. Terkadang dengan beristirahat sejenak dan mendengarkan musik dapat sedikit merefresh otak. Belajar jangan hanya untuk menggugurkan kewajiban. Artinya, belajar selain sebagai kewajiban, juga harus menjadi kebutuhan yang harus segera di penuhi untuk menambah ilmu karena kebodohan dekat dengan kemiskinan.

Berbagai upaya terus dilakukan oleh dosen atau pendidik dalam rangka memberikan pelayanan dan pembelajaran terhadap mahasiswa agar memiliki kesadaran dan semangat yang tinggi akan tugas dan tanggungjawabnya sebagai mahasiswa terutama pada saat proses pembelajaran berlangsung baik melalui pemberian tugas kerja maupun dengan diskusi kelompok. Namun berbagai upaya yang dilakukan tersebut tidak banyak memberikan perubahan yang berarti terhadap perkembangan kepribadian dan semangat dalam melaksanakan tugas dan tanggungjawabnya sebagai pebelajar. Dalam upaya menurunkan perilaku kejenuhan dalam belajar mahasiswa diperlukan intervensi dari pendidik melalui upaya dan tehnik secara terpadu dan tepat. Ice Breaking merupakan suatu aktivitas kecil dalam suatu kegiatan yang bertujuan agar peserta mengenal peserta lain dan merasa nyaman dengan lingkungannya. kegiatan ini biasanya berupa suatu humor, kadang berupa kegiatan yang cenderung memalukan, kegiatan berupa informasi, pencerahan, atau dapat juga dalam bentuk permainan sederhana. Kalau dipilih kegiatan yang cocok, ice breaking bisa menjadi momen yang efektif untuk memfasilitasi pondasi, opening, bahkan kesuksesan sebuah kegiatan secara keseluruhan. Sesuai namanya, Ice breaking dibuat untuk "memecahkan es" pada suatu acara baik itu pesta, seminar dan pelatihan, maupun pertemuan yang lebih formal seperti proses belajar dan pembelajaran. Kunci dari kesuksesan ice breaking adalah mengkhususkan kegiatan ini untuk menunjang agenda yang ada dan mencairkan suasana. Penelitian ini dilakukan di salah satu perguruan 
tinggi yang ada di Bima yaitu STKIP Bima, dengan tujuan ingin mengetahui apakah ice breaking dapat menurunkan perasaan jenuh mahasiswa dalam kegiatan pembelajaran. Hal ini didasari oleh munculnya berbagai perilaku mahasiswa pada saat kegiatan pembelajaran berlangsung seperti adanya perasaan acuh tak acuh dalam mengamati pelajaran yang diberikan, kurang semangat, selalu gelisah, rasa enggan, malas, lesu dan merasa tidak bergairah dalam belajar. Dalam penelitian ini peneliti menetapkan 5 jenis ice breaking kemudian secara bergantian diberikan ketika mahasiswa menunjukan perilaku jenuh pada saat kegiatan pembelajaran berlangsung selama satu semester berjalan. Penerapan ice breaking diperuntukan bagi subyek penelitian yang telah ditetapkan dalam kelompok eksperimen sedangkan kelompok control tidak diberikan perlakuan. Untuk menunjang penelitian peneliti menggunakan tehnik pengumpulan data berupa angket skala 4 dengan jumlah item pertanyaan sebanyak 43 item yang disusun berdasarkan indicator variable penelitian. Berdasarkan hasil analisis statistik inferensial uji Wilcoxon diperoleh informasi bahwa hasil pretest pada kelompok eksperimen dan kelompok kontrol sebelum penerapan ice breaking berada pada kategori tinggi. Hasil posttest menunjukan ada penurunan angka pada kelompok eksperimen bila dibandingkan dengan hasil pretest, sedangkan pada kelompok kontrol tidak terjadi perubahan signifikan dan terlihat stagnan ini berarti bahwa HO "penerapan ice breaking tidak efektiv untuk menurunkan perilaku kejenuhan dalam belajar dinyatakan ditolak dan $\mathrm{H} 1$ "penerapan ice breaking efektif untuk menurunkan perilaku kejenuhan dalam belajar dinyatakan diterima. Jadi, secara umum hasil penelitian ini menjelaskan bahwa ice breaking merupakan tehnik yang sangat baik untuk menurunkan perasaan jenuh mahasiswa. Dimana melalui pemberian perlakuan ice breaking ini mahasiswa dapat lebih semangat dan percaya diri agar memiliki keyakinan akan kemampuan dalam dirinya, memiliki rasa dan mampu bersikap optimis, bersikap obyektif, meningkatkan rasa tanggungjawab, dan mampu berpikir rasional dan realistis serta selalu tetap semangat terhadap segala situasi yang dihadapi. Juga dapat dikatakan bahwa pada dasarnya ice breaking berpengaruh besar dalam memberikan kontribusi terhadap potensi dan proses perkembangan aspek kognitif individu yang dapat mendorongnya untuk lebih percaya diri dan lebih bersemangat.

\section{PENUTUP}

Berdasarkan hasil penelitian tentang penerapan ice breaking untuk menurunkan perilaku kejenuhan belajar mahasiswa Sekolah Tinggi Keguruan dan Ilmu Pendidikan Bima, dapat dikemukakan beberapa kesimpulan sebagai berikut:

1. Tingkat kejenuhan belajar mahasiswa hasil pretest baik terhadap kelompok eksperimen maupun kelompok kontrol berada pada kategori tinggi. Namun demikian, setelah diberi perlakuan ice breaking menunjukkan adanya perubahan positif terhadap kelompok eksperimen yang ditandai dengan penurunan angka perilaku jenuh dari kategori tinggi menjadi kategori rendah, sedangkan bagi mahasiswa kelompok kontrol yang tidak diberikan perlakuan tidak menunjukkan perubahan yang berarti atau tetap dalam kategori tinggi.

2. Penerapan ice breaking dapat menurunkan perilaku kejenuhan belajar mahasiswa Sekolah Tinggi Keguruan dan Ilmu Pendidikan Bima (STKIP) Bima.

Untuk menjadi pendidik yang profesional harus diawali dari semangat membara yang memancar dari diri, dan salah satunya semangat menjadi pendidik inovatif. Untuk menjadi pendidik inovatif diperlukan kerja keras dan menjadikan diri sebagai pendidik "bertelinga lebar", sekaligus "bertelinga tertutup". Jangan paksakan peserta didik untuk menikmati pembelajaran yang kita lakukan. 
berikut:

Sehubungan dengan kesimpulan penelitian diatas, maka diajukan saran-saran sebagai

1. Bagi lembaga pendidikan yang memiliki kewenangan untuk mencetak tenaga pendidik yang berkompeten hendaknya dapat meningkatkan strategi dan upaya dalam meningkatkan kemampuan output yang memiliki kompetensi maksimal.

2. Bagi guru dan dosen, hendaknya mampu menerapkan model pengajaran yang lebih bervariasi agar setiap mahasiswa yang dihasilkan dapat mengambil pelajaran dan meningkatkan kemampuan dirinya dalam mengaktualisasikan ilmunya di lingkungan pendidikan/sekolah, masyarakat dan keluarga.

Bagi mahasiswa, hendaklah memiliki semangat dalam diri agar apapun yang dipelajari lebih mudah diserap dan dipahami guna meningkatkan kualitas diri.

\section{DAFTAR PUSTAKA}

\section{Buku}

Soenarno A, Ice Breaker Permainan Atraktif-Edukatif, (Yogyakarta: Andi offset, 2005)

Adi W. Gunawan, Genius Learning Strategy, (Jakarta: Gramedia Pustaka Utama, 2012)

Anggani S, Sumber Belajar dan Alat Permainan,(Jakarta: PT Grasindo,2006)

Basri, Hasan.1966. Remaja Berkualitas Problematika Remaja dan Solusinya. Yogyakarta : Pustaka Pelajar

Sugiyono, Metode Penelitian Pendidikan, (Bandung : Alfabeta, 2010)

--------, Statistika untuk Penelitian, (Bandung: Alfabeta, 2010)

Suharsimi Arikunto, Prosedur Penelitian Suatu Pendekatan Praktek, (Jakarta: Rineka Cipta, 2006)

Sunarto, Ice Breaker dalam Pembelajaran Aktif, (Surakarta: Yuman Pressindo,2011.

Internet

http://wawasanbk.blogspot.com/2012/10/faktor-penyebab-kejenuhanbelajar.html

http://mahasiswasyariah.wordpress.com/2013/03/19/mengatasi kejenuhan-dalampembelajaran-apa-solusinya/

http://icebreaker-piranti-baku-pemandu.html 